\title{
Built environment, Peak Hours and Route Choice Efficiency: An Investigation of Commuting Efficiency using GPS Data
}

August 29, 2016

\author{
$\mathrm{Na} \mathrm{Ta}$ \\ School of Geographic Sciences, East China Normal University \\ No. 500 Dongchuan Road, Shanghai 200241, China \\ Email: tanapku@gmail.com \\ Ying Zhao (Corresponding Author) \\ School of Tourism Management, Sun Yat-sen University \\ No.135 Xingangxi Road, Guangzhou 510275, China \\ Email: zhaoy233@mail.sysu.edu.cn \\ Yanwei Chai \\ Department of Urban and Economic Geography \\ College of Urban and Environmental Sciences \\ Peking University, Beijing 100871, China \\ E-mail: chyw@pku.edu.cn
}




\section{Acknowledgement}

This research received grants from the China Postdoctoral Science Foundation (No. 2015M580305) and the National Science Foundation of China (No.41571144, 41501172).

Abstract: Commuting efficiency measures the impact of commuting on urban spatial and social environments. Urban policies aim to reduce commuting distances and improve commuting efficiency by supporting mixed land-use and job-housing balance. Many studies have addressed these issues by examining excess commuting at the aggregate level, and most aggregated measurements of excess commuting are based on home-to-work commuting flows between zones. However, residents' travel behaviour does not consist solely of rational attempts at minimizing commuting distances but is instead affected by commuting hours, the complexity of the commuting chain and the built environment. Thus, commuting efficiency must be studied at the individual or disaggregated levels. This paper examined individual commuting efficiency in suburban Beijing using a GPS-facilitated activity-travel survey and investigated the differences in commuting distance and route choice efficiency between morning and evening peaks. Notably, in so doing, we considered non-work stops, and also explored the impact of urban spatial factors - in both residential and working areas - on commuting efficiency using multilevel mixed effects generalized linear models. The findings suggest that there are significant differences in commuting distance and commuting efficiency between morning and evening peaks based on the nature of commutes. Residents working in city centres or with jobs near railway stations, with higher road network densities or with lower facility densities seem to be more adept at selecting optimal routes.

Keywords: Commuting efficiency; built environment; peak hour; suburbs; China 


\section{Introduction}

Geographers have long been interested in urban commuting and the challenges it poses for urban societies (Cervero and Duncan, 2006; Horner, 2004; Zhou et al., 2014a; Chai et al., 2016). Studies linking urban form and commuting behaviour show that shorter commuting trips will reduce dependency on cars and maximize sustainable outcomes (Ciscal-Terry et al., 2016; Loo and Chow, 2011; O'Kelly and Lee, 2005; Thomas and Tutert, 2015). Other studies argue that widespread use of transportation contributes to increasing distances between home and work, forcing people to navigate the temporal and spatial constraints that commuting generates (Urry, 2007: 120). People who have lengthy commutes may reside in congested and unhealthy environments and have limited involvement in their households and communities (Putnam, 2000: 212; Urry, 2012).

Commuting efficiency has received substantial attention as a means of understanding the impact of commuting on urban spatial and social environments, with the goal of minimizing the distance travelled through urban areas. The most common measure of commuting efficiency is excess commuting, which is generally defined as the difference between the observed commute and the theoretical minimum commute resulting from a given spatial configuration of housing and jobs. A rich literature has established benchmarks of excess commuting at aggregated levels such as cities or regions (Kanaroglou et al., 2015); thus, higher levels of excess commuting indicate less efficient commuting patterns and greater potential for reduced commuting (Hamilton and Röell, 1982). However, the majority of aggregated measurements of excess commuting are based on home-to-work commuting flows between zones, which depend heavily on zonal partitioning schemes (Niedzielski et al., 2013). Moreover, assumptions regarding uniform job-housing distribution and maximizing travel utility by optimizing travel distances are somewhat unrealistic (Horner, 2002; Murphy, 2009; Papinski and Scott, 2013). The aggregated methodology used by commuting efficiency studies can reveal general information about an area as a whole but cannot reflect the detailed behaviour of individuals in specific contexts (Horner and Wood, 2014). For instance, factors such as job-housing balance (Loo and Chow, 2011; Zhou et al., 2014a), 
transportation networks (Thomas and Tutert, 2015), and terrain conditions and information (Ciscal-Terry et al., 2016) can strongly influence the efficiency of route choices, leading to different commuting levels among individuals.

Because of the importance of targeting research to specific policy implications, route choice efficiency has been proposed as a measurement of 'wasteful' commuting at the individual level (Papinski and Scott, 2013). Using accurate route data obtained by Global Positioning System (GPS) logs (Ciscal-Terry et al., 2016; Thomas and Tutert, 2015), this measurement capability offers an opportunity to investigate the commuting efficiency of a given person in a specific context (Papinski and Scott, 2013). However, commuting efficiency studies at the individual level still face substantial methodological and empirical challenges. First, the impact of commuting behaviour on commuting efficiency is poorly understood. Not only do commuters detour to perform non-work activities during commuting trips, they may also choose different travel modes and commuting routes during morning and evening peaks (Bhat, 1997; McGuckin et al, 2005; Noland and Thomas, 2007). By no means do the findings from research on commuting behaviour suggest that commuting efficiency is underestimated when we hypothesize that individuals travel directly from home to work using optimal routes (Papinski and Scott, 2013). Second, commuting efficiency measurements are based on car-travel conditions in Western countries. Studies of route choice using public transit are insufficient. Third, previous studies have explored the influence of aggregate spatial structural factors on commuting distances based primarily on origin-destination pairs. Because the spatial resolution of observed route traces has been improved by tracking technologies, studies of spatial impacts should consider not only residential areas but also workplaces (Frost et al., 1998). However, it remains unclear how these environments affect single routes and specific commuting efficiencies.

Informed by Papinski and Scott (2013), this paper uses the concept of route choice efficiency to study the determinants of commuting efficiency. Using a case study of suburban Beijing (a typical suburban area representative of megacities in developing countries where serious traffic problems must be solved by effective policy interventions) this paper seeks to answer the following three 
questions: (1) What is the nature of commuting behaviour in Beijing? (2) What are the differences in commuting distance and commuting efficiency between morning and evening peaks, considering non-work stops and travel modes? (3) How have urban spatial factors in both residential and work areas changed to improve commuting efficiency? This paper will specifically contribute to the literature and improve route choice efficiency measurements by considering multiple modes of travel and the types of detours taken between peak hours. These research questions are answered in the four sections following this introduction. Section 2 summarizes the academic literature on commuting behaviours and commuting efficiency. Section 3 presents the characteristics of datasets and discusses the method used to measure route choice efficiency. Section 4 presents the results of descriptive and multivariable analysis, followed by conclusions and suggestions for future research.

\section{Literature review}

The concept of commuting efficiency is used to evaluate job-housing relationships by comparing observed and theoretical commuting behaviour (Horner, 2004; Niedzielski, 2006). In particular, excess commuting has been widely used to measure commuting efficiency at the aggregate level. First introduced by Hamilton and Röell (1982), excess commuting is defined as non-optimal commuting travel that is undertaken as a result of the distribution of residences and workplaces (Giuliano and Small, 1993; Hamilton and Röell, 1982; Small and Song, 1992). Normally, it is calculated as the difference between the average actual commuting distance and the optimal (theoretically minimal) commuting distance in a city. Measures of excess commuting typically provide a summarised commuting efficiency level for a city as a whole (Horner, 2002). The previous literature has shown that excess commuting varies $40-80 \%$, meaning that the spatial configurations of job-housing relationships explain approximately $20-60 \%$ of commuting trip distances/time (Frost et al., 1998; Giuliano and Small, 1993; Horner and Murray, 2002; Kim, 1995; Murphy, 2009; Niedzielski et al., 2013; Small and Song, 1992; Zhou et al., 2014a).

Moreover, levels of excess commuting are influenced by the scales of analytical units and zonal 
patterns. Studies of excess commuting often use job and home locations that are aggregated into zones, and the variations in the scales of analysis used in different studies have produced widely divergent assessments of excess commuting. This is referred to as the Modifiable Areal Unit Problem (MAUP) (Horner and Murray, 2002; Niedzielski et al., 2013; Small and Song, 1992). For example, Horner and Murray (2002) studied commuting in Boise, Idaho and showed that excess commuting varies from $26.21 \%$ ( 25 zones) to $48.07 \%$ ( 286 zones).

Commuting efficiency studies at disaggregated levels are believed to contribute to our understanding of the important details of urban commuting efficiency and to help overcome the MAUP. Bottom-up approaches, which take individual level data and aggregate them into zones, have become a new trend in commuting efficiency studies. Some studies have attempted to mitigate the scale effect by aggregating disaggregated commuting data at different scales (Horner and Murray, 2002; Niedzielski et al., 2013; Horner and Wood, 2014). Although these studies still focused on the MAUP effects of excess commuting at the metropolitan level, they also demonstrated the possibility of more spatially sophisticated studies of commuting efficiency. Other prior studies have attempted to develop a disaggregated approach to excess commuting calculations. Niedzielski (2006) first offered a framework of disaggregated excess commuting based on spatial disaggregation to analyse intra-metropolitan commuting efficiency. Other studies have addressed the heterogeneity of commuting efficiency among social groups, based on differences such as occupation and gender (O'Kelly and Lee, 2005; O'Kelly et al., 2012; Sang et al., 2011). Hu and Wang (2015) used a Monte Carlo simulation method to estimate individual locations and optimal commuting patterns. While these studies still confronted the important challenge of disaggregation and do not address the specific commuting patterns of individuals, commuting efficiency studies at the disaggregated level have attracted increased attention.

To address the commuting behaviour of individuals, route choice efficiency is used to study commuting efficiency at the individual level (Papinski and Scott, 2013). Thanks to the high resolution of GPS tracking data, even single paths can be identified in transportation networks, and the directness of commuting routes can be investigated at the individual level. By comparing 
actual commuting routes with the shortest possible commuting routes for each individual, route choice efficiency helps reveal important information about a given individual's commuting efficiency in a specific context.

However, prior studies still face some limitations, both methodologically and empirically. First, existing studies have studied only automobile commuting (Papinski and Scott, 2013), concluding that most drivers choose suboptimal routes for their home-to-work trips. Although this form of commuting may represent the most common mode in Western countries and is easy to calculate, both public transit and non-motor travel are common in developing countries (Beijing Transportation Research Centre, 2013). However, there is no existing methodology for route choice efficiency studies of public transit. Second, prior studies have examined only home-to-work commuting without any non-work stops (Papinski and Scott, 2013). In reality, commuting behaviour is becoming more and more complex as individuals incorporate both personal and household activities into the same trips (Papinski and Scott, 2013). Third, prior studies have only analysed the commuting efficiency of home-based commuting trips. However, two-way commuting trips can be different due to the impact of traffic peaks, space-time constraints and individuals' daily schedules.

To capture the attention of urban scholars and planners, research on route choice efficiency that aims to understand why and how much individuals deviate from optimal commuting routes should integrate the full diversity of commuting patterns. In particular, commuting behaviour encompasses many types of trips, including complex trip-chains, flexibility and multi-mode choices; these are under-examined in commuting efficiency studies. Existing commuting studies have demonstrated the high proportion of multi-purpose commuting trips in both the US and in Europe (Bhat, 1997; Lockwood and Demetsky, 1993; McGuckin et al, 2005; Noland and Thomas, 2007). Trip-chaining significantly impacts commuters' travel times and route choices (McGuckin et al, 2005). Individuals who make stops along their commuting trips live farther from work and travel longer distances than those who do not make such stops (Justen et al., 2013; McGuckin et al, 2005). Commuting flexibility is a concept first introduced by De Palma and Lindsey's (2002) 
comparison of morning and evening commuters. Subsequently, Li et al. (2005) further discussed flexibility in terms of route choice and the presence of stronger temporal constraints in the evening than in the morning, while Shen et al. (2013) explored the intra-personal day-to-day variability of commuting behaviour. These studies note the variability and diversity of commuting processes and emphasize that new research must consider morning/evening differences based on multi-day observations. Regarding commuting modes, most studies have discussed the route choices faced by automobile drivers (Ciscal-Terry et al., 2016; Li et al., 2005; Papinski and Scott, 2013), but few have explored the situations of commuters who use public transit and non-motorized transportation. Public transit trips can be complicated and capturing their component parts may be difficult, and non-motorized commuting may not be the key contradiction inherent in traffic and the built environment. For these reasons, little attention has been paid to either of these forms of commuting. However, these trips are also essential aspects of commuting behaviour, and studies of commuting efficiency should expand their frameworks and associated methods to analyse both public transit and non-motor commuters (Murphy, 2009; Zhou et al., 2014a, b).

Moreover, the built environment has a major impact on commuting efficiency. Research on excess commuting has linked commuting efficiency with urban form, indicating that job-housing balance and mixed land use may reduce excess commuting at the aggregate level (Chowdhury et al., 2013). At the local level, the relationship between the built environment and commuting patterns has also been intensively investigated (Cervero and Duncan, 2006; Frank and Pivo, 1994). Many studies have found that high density planning, mixed land use and living close to the city centre are associated with shorter commutes (Ewing and Cervero, 2010). Although most studies only focus on the built environment around the home, the built environment around work locations also has a strong influence on commuting behaviour (Frank and Pivo, 1994; Maat and Timmermans, 2009).

Although there are hot debates regarding commuting efficiency in Western countries, little attention has been paid to commuting issues in China. China's rapid urban expansion and residential suburbanization have had a considerable impact on commuting patterns (Feng et al., 2008; Wang and Chai, 2009; Zhao and Chai, 2013). However, few Chinese studies have discussed 
commuting efficiency in the context of urban transformation. There are a few exceptions, including Liu et al.'s (2008) estimation in Guangzhou; Zhou et al.'s (2014b) study of the Danwei Legacy in Xi'an, and Zhou et al.'s (2014a) study of excess commuting based on Smartcard data in Beijing. Zhou et al (2014a) were the first to incorporate public transport users (e.g., by including bus trips in commuting efficiency measurements); they noted that easy bus access from both residential and work locations is an effective way to reduce shifts from bus to car usage. Such efforts show that commuting efficiency is an important aspect of planning and policy in the context of the transformation of urban China, but little attention has been paid to this topic and its potential implications.

Within the context discussed above, this study investigates commuting efficiency by suburban residents in Beijing from the perspective of route choice efficiency. This paper contributes to existing studies in three ways. First, it studies rush-hour differences in route choice efficiency between morning and evening peaks and provides an intuitive way to explore the influence of space-time constraints on commuting behaviour. Second, it outlines the potential role of non-work stops in route choice efficiency by distinguishing among types of detours. The impact of non-work stops is important because individuals may not always try to minimize their commuting distance/time to maximize utility when they must make necessary detours. It is essential to recognize this when investigating the core hypothesis of traditional excess commuting research. Finally, this study offers an analysis of route choice efficiency based on diverse modes of travel, including car, public transit, bicycle, and walking. Because most studies of commuting efficiency that are based on disaggregated data focus on car travel, this study provides an opportunity to compare differences in levels of route choice efficiency among different travel modes. Moreover, the built environments of both residential areas and workplaces (as well as individual socio-demographics) are considered as explanatory variables.

[Figure 1 about here] 


\section{Data and method}

\subsection{Data and study area}

This study uses data from an activity-travel survey dataset collected in an inner suburban region in Beijing between Oct. and Dec. 2012. As China's political, cultural, and economic centre, Beijing had a total population of 20.69 million in 2012 (Beijing Statistic Bureau, 2013). Although Beijing is still a monocentric metropolitan area with a few emerging job sub-centres, it has undergone rapid population suburbanization since the 1980s (Feng et al., 2008). Thus, many suburban residents suffer from having poor accessibility to employment and other urban opportunities, leading to long car trips and large activity spaces (Kwan et al., 2014; Tana et al., 2016; Zhao et al., 2011).

This study focuses on the Shangdi-Qinghe area in Beijing, which is an inner suburban area consisting of 42 neighbourhoods with 240,000 residents (Figure 2). We select this inner suburban area because it faces serious long-distance commuting problems and congestion due to job-housing imbalance and car dependency. A subsample of local residents were recruited through a multi-stage cluster sampling procedure based on $0.5-1 \%$ of the total population in all communities (except army compounds and urban villages); that is, 579 residents from 23 communities (Chai et al., 2014). A total of 543 residents agreed to participate and 480 of them completed the entire survey.

Data were collected via person-based GPS tracking and a web-based activity-travel survey. The respondents were asked to carry a GPS tracking device and to log their activities on a survey website for seven consecutive days. The GPS positioning technology logged the space-time coordinates of each participant every 30 seconds and uploaded the data to a network server every 5 minutes. Finally, 480 respondents were selected from 23 communities to participate in a 7 -day survey. 
[Figure 2 about here]

\subsection{Routes and commuting distance}

Actual routes and distances were calculated in ArcGIS. GPS provides positional information at fine temporal and spatial scales. The commuting trips were extracted, including all the GPS points between the first point (leaving home/workplace) and the last point (entering workplace/home). Then, the point-to-line tools in ArcGIS 10.2 were used to formulate and calculate the actual commuting distances for the selected respondents by linking together all the GPS points in each person's commuting route.

The shortest path and distance were calculated according to travel mode, which is the same as actual commuting travel. The fixed travel mode hypothesis is realistic, as individuals may choose their commuting mode not only based on their income, car ownership, work duration, time budget and travel fees, but also based on habits and norms (Bhat, 1997; Klöckner and Matthies, 2004). Furthermore, choice of travel mode, stops made, and route are often linked together in the travel decision-making process (Bhat, 1997; Ye et al., 2007). For car travel and non-motor travel, the shortest paths, based on distance between home and work, were generated using the network analyst extension in ArcGIS 10.2 (Papinski and Scott, 2013). The road network used in network analysis included all the urban roads in Beijing city, from highways to cul de sacs, connected to residential communities. For public transit such as travel by bus and railway, the shortest paths were generated using online Baidu maps ${ }^{1}$ by searching for the most efficient route between an individual's residential neighbourhood and work place. The route includes all transfers between travel modes throughout the individual's journey. Calculating efficient routes considered operation time and peak hours by setting the departure time in the Baidu map. The most important

\footnotetext{
${ }^{1}$ Baidu Maps is a web mapping service application provided by the Baidu company, which provides planned routes for travel by foot, car, or with public transportation. It is considered the most authoritative and the most rapidly updated source of maps in mainland China. (Wiki) The Baidu map we use is from 2014.
} 
advantage of this method is that the shortest routes generated are based on the current distribution of public transport lines. The disadvantage is that when spatial information on residential locations and workplaces is not completely accurate, the selected routes may differ from reality.

\subsection{Sample characteristics}

In this paper, we focus on the commuting behaviour of suburban residents. For this reason, we selected a subsample using the weekday data of full-time employed residents aged 20-60 years. To compare morning and evening peaks, the selected survey day of a given participant should have two-way commuting trajectories and diary data for peak hours. This led to a pre-subsample of 269 persons with commuting information on 786 trip-pairs.

The pre-subsample was examined by comparing the calculated actual route distance and the shortest path distance. A total of 6 days were excluded due to an extreme actual route distance shorter than $500 \mathrm{~m}$, and 12 days were excluded due to an extreme shortest path distance shorter than $500 \mathrm{~m}$. Approximately 27 days were excluded because the commuting routes did not link to participants' permanent addresses. Because GPS tracking may require one to five minutes to relocate when people walk from indoors to outdoors, commuting trips that lacked accurate origin or destination signals were excluded. Moreover, when people go through areas with high densities of high-rise buildings, positioning is insufficiently accurate, and thus 34 days were excluded. This led to a final sample of 161 residents with 329 days. Three files, including GPS data, activity-travel diaries, and participant characteristics were combined to study commuting efficiency.

Table 1 shows the overall sample characteristics. The share of female respondents $(51.2 \%)$ is slightly higher than males (48.8\%). More than $85 \%$ have Beijing's hukou, indicating that they are local residents. Most of the respondents are well educated, with a bachelor's degree or higher, and $61.9 \%$ of the respondents have a monthly income between 2000 and $6000 \mathrm{RMB}$, which is a 
middle-level income in Beijing. Most of the respondents are married, and more than half of the married respondents have children under 16 years old. Approximately $30 \%$ respondents have a job near home and another $35 \%$ work in the city centre (the distribution of workplaces is shown in Figure 1).

[Table 1 about here]

\subsection{Measurement of commuting efficiency}

Following Papinski and Scott's (2013) method, both morning and evening commuting efficiency at the individual level are discussed in this paper. This study defines commuting efficiency as the degree to which an actual route corresponds to the shortest path based on distance. The commuting efficiency of each commuting trip in the sample was measured by a route directness index (RDI):

$\mathrm{RDI}=A P D S R D-1 * 100(\%)$,

where ARD is the actual route distance and SPD is the shortest path distance. The RDI is a continuous variable from zero. The number zero represents the most efficient route, with no detour.

There are two types of detours in commuting behaviour: necessary and unnecessary. Necessary detours are often fairly efficient, as individuals may travel greater distances for non-work activities to fulfil their needs. This type of detour may reflect the distribution of urban facilities or personal preferences of activity location. Detours may increase with the number of non-work stops. Unnecessary detours are inefficient, as individuals may travel longer distances without completing any non-work activities. This type of detour may be due to traffic congestion, incomplete travel information, etc. For a rational individual, unnecessary detours should be reduced to make travel more sustainable. Therefore, we used non-work stops made while commuting as the index to distinguish these two types of detours. If individuals make no non-work stops, the detours are 
defined as unnecessary.

\subsection{Analytical strategy and modelling}

Multilevel mixed-effects generalized linear models are used to study commuting efficiency. A general two-level model can be written as (Goldstein, 1986)

$y i j=\beta O i j+\beta 1 x i j+\varepsilon i j$

Where $\mathrm{y}_{\mathrm{ij}}$ is the dependent variable. This means that the efficiency of commuting behaviour $\mathrm{i}$ (level 1) by person $\mathrm{j}$ (level 2) is a function of an independent variable $\mathrm{x}_{\mathrm{ij}}$ whose effect is given by the regression coefficient $\beta_{1} . \varepsilon_{\mathrm{ij}}$ is a random variable describing the distribution of the residuals, and $\beta_{0 \mathrm{ij}}$ represents the intercept or constant.

A hierarchical or multilevel model can account for the nested structure of the data: commuting efficiency is a characteristic of the commuting behaviour performed by respondents living in different communities. Ideally, three levels should be applied to take into account the variations in peak hours, individuals and communities. However, when more levels are used, the limited degrees of freedom would render the parameter estimates unstable and the results unreliable. Finally, a two-level model takes into account inter-personal differences. Multilevel regression modelling relaxes the independence assumption in OLS regression modelling. This independence assumption is often violated in social science research to produce biased outcomes (Snijders and Bosker, 1999).

In this study, we built four multilevel mixed-effects generalized linear models. Models 1 and 2 use the logarithmic form of commuting efficiency for all commuting trips and for commuting without stops (which represent unnecessary detours) as the dependent variables, respectively. Models 3 and 4 use the logarithmic form of commuting efficiency during morning peaks and evening peaks, respectively. We focused on the impacts of peak hours and other commuting characteristics on commuting efficiency, including number of stops and travel mode. Other variables that may have 
significant effects on commuting efficiency are also controlled in the models, including socio-demographic characteristics and spatial factors. Socio-demographic characteristics that may influence route choice are included, such as gender, age, income, education level, hukou status and household structure. Spatial factors represent the built environment in both the residential location and the working location, including facility density, distance to the nearest railway station and road network density. Facility density was derived based on the number of facilities (such as retail stores, entertainment facilities and public service facilities) within a 1000-meter buffer area around each participant's home/workplace using ArcGIS 10.2. It is regarded as a proxy for local access to goods and services. Distance to the nearest railway station is used to measure neighbourhoods' access to transportation. This distance was calculated as the linear distance between the home/workplace of a participant and the nearest railway station. The roadway density measure, which is used to evaluate the density of the street network, evaluated the length of the road network within a 1000-meter buffer area. It is used to assess the design of the built environment. Finally, work location is also included as a dummy variable to evaluate the impact of urban structure.

\section{Results}

\subsection{Descriptive analysis}

Table 2 shows the summary statistics for commuting behaviour in Shangdi-Qinghe disaggregated by commuting peaks. Overall, the average commuting distance of these suburban residents is $15.95 \mathrm{~km}$ with 0.13 stops, and the average RDI is $58 \%$. Commuting efficiency in Beijing appears to be lower than in Western countries, and few residents appear to take routes that are the same as the shortest routes (Papinski and Scott, 2013). For those who do not perform any non-work activities during their commutes (meaning that they take unnecessary detours), the average commuting distance is longer and RDI is lower - perhaps because people with longer commuting distances prefer to go directly home (Justen et al., 2013). The lower RDI values for commuting without stops indicate that commuting efficiency is related to the number of stops made during 
commuting and that individuals prefer to make fewer unnecessary detours than necessary detours.

There are significant differences in commuting distance and commuting efficiency between the morning and evening peaks. Based on the averages, residents commute slightly shorter distances $(15.81 \mathrm{~km})$ and have fewer non-work stops (.09) during morning peaks than during evening peaks $(16.09 \mathrm{~km} / .18)$. This result is consistent with the existing literature, which reports that residents have fewer space-time constraints and tend to conduct more discretionary activities during their evening commutes than during their morning commutes (Bhat, 1997; Lockwood and Demetsky, 1993; Schwanen and Dijst, 2003). For those who make unnecessary detours, the morning commute is shorter and the evening commute is longer; and the differences are significant. The average RDI value for evening commuting is slightly higher than for morning commuting, for both the total sample and the sample without stops.

[Table 2 about here]

There are significant differences in commuting distance and commuting efficiency when we consider the nature of commuting trips. The number of stops has a significant impact on route choice efficiency, but only for morning commuting. Having one stop during the morning commute leads to higher RDI value, while commuting non-stop significantly increases commuting efficiency. This means that individuals do take more necessary detours to engage in activities such as transporting family members or going to day-care centres during their morning commutes. Average commuting distances and numbers of stops vary by travel mode, however, there are no significant differences in RDI values. Not surprisingly, walking trips are the shortest in distance, followed by bicycle trips for both morning and evening commuting. The average distance of public transit commutes is slightly longer than that of automobile commutes during morning peaks; the reverse is true for evening peaks. Residents make most of their non-work stops during car trips, followed by public transit, bicycle, and, finally, walking trips because car users have more mobility and can access more urban opportunities than people using other modes of transport (Kwan and Kotsev, 2015) and because residents using public transit can conduct non-work 
activities at transfer stations.

[Table 3 about here]

\subsection{Multivariable analysis}

The first and second multilevel linear regression models in Table 4 analyse the RDI values to compare actual routes with their shortest paths for all commuting trips and for commuting without stops, respectively. Model 3 and model 4 in Table 4 compare the results of multilevel linear regression models for RDI values during morning and evening peaks.

The result shows that peak commuting hour has a significant impact on RDI values in both models and that evening commuting trips are more inefficient than morning trips. The number of locations an individual can access increases as his or her time budget expands (Kwan, 2000). As residents have fewer space-time constraints in the evening (Shen et al., 2015), they are more likely to take suboptimal routes to perform more non-work activities or avoid congestion.

Engaging in non-work activities has a significant impact on route choice efficiency, which illustrates the difference between necessary and unnecessary detours. As shown in model 1, when controlling for other factors, having only two or more stops in the total commute has a significant impact on RDI values, such that that making more stops leads to more efficiency. One possible explanation is that when an individual needs to perform more activities in an expanded time window, they are more likely to chain these activities around their commuting route. The influence of non-work stops on route choice efficiency reflects time-specific circumstances. Making non-work stops during morning commuting will lead to more detours, but this is not the case for evening commuting. This may be because many of the non-work stops during morning peaks serve more basic functions with higher spatial fixity (for example, driving children and other family members) (Bhat, 2001). 
The mode of travel also impacts the choice of a commuting route. Overall, non-motor travel shows greater advantages in commuting efficiency for both the total sample and the subsample with no stops. Compared to commuting by bicycle, commuting by car and public transit is less efficient. Furthermore, car commuting is much less efficient than non-motor commuting during evening peaks than during morning peaks. This may be because car drivers not only detour to avoid congestion but also may have a smaller set of alternative routes. Additionally, car drivers may have more freedom to engage in discretionary activities that diverge from their optimal commuting routes during evening peaks (Bhat, 1996; Schwanen and Dijst, 2003).

All four models exhibit strong impacts of job-housing relationships. Residents with jobs near their homes seem to be less efficient in their route choices. This is inconsistent with Papinski and Scott (2013), who found that a shorter commuting distance leads to more alternatives in route choice. One possible explanation for this finding may be that living and working at a walkable distance gives people more opportunities to perform non-work activities during their commutes, leading to more necessary detours. Another explanation is that the shortest path algorithm in ArcGIS excluded the distance from home to the end of the road and the distance from the end of road to the workplace from the total distance calculated (thus, paths in neighbourhoods that are not included in our dataset are not calculated). Thus, the shortest path at the local level will be much shorter than the actual one. With the exception of morning commuting, working in the city centre leads to greater commuting efficiency. This is due to the fact that suburban residents working in the city centre have longer commuting distances and tend to take the express routes proceeding directly from or to their homes. As all commuters usually have less temporal flexibility in the morning than in the evening, and the differences are not significant (Li et al., 2005).

The impact of the built environment in work areas, rather than in residential areas, has a significant impact on commuting efficiency. Respondents who have jobs near railway stations, near areas with higher road network density, or near areas with lower facility density seem to be more adept at selecting optimal routes. First, compactness and high public transit accessibility 
near the workplace discourage car commuting (Shiftan and Barlach, 2002). Second, a high density of urban opportunities near the workplace may lead to fewer detours when commuting, as individuals can fulfil non-work needs near their workplaces. Existing literature has indicated that high accessibility at the workplace leads to more simple commuting trips (Krizek, 2003). However, the impact of the built environment on neighbourhoods is not significant. This confirms the findings of previous studies that work location is actually more important than residential location (Maat and Timmermans, 2009). There is little difference in the impact of the built environment between morning and evening commuting, except for the distance from the work location to the nearest railway station. This shows that having a job close to a railway station may impact route choice in the morning due to the extensive space-time constraints during the morning peak.

Commuting efficiency also varied with gender, household structure, income, and education level. Consistent with Papinski and Scott (2013), females are more efficient commuters whether or not they conduct non-work activities during their commutes, and the differences between males and females are larger during morning commutes. Experiencing more conflicts between household and employment responsibilities will lead to more space-time constraints on travel, thus resulting in more optimal route choices in commuting (Feng et al., 2013; Ta et al., 2015). However, household structure has different impacts on the efficiency of men's and women's chosen routes due to bargaining over household labour divisions, such that women with more household responsibilities may take more necessary detours to meet their household care needs (Johnston-Anumonwo 1997; Scheiner and Holz-Rau 2012). Residents with less personal income and residents with high education levels are less efficient commuters. It seems that lower income groups tend to travel beyond their optimal distances even without performing any non-work activities, indicating more unnecessary detours for disadvantaged people.

[Table 4 about here] 


\section{Conclusion and discussion}

Commuting efficiency is a powerful perspective to adopt when exploring the relationship between urban environments and residential behaviour. Chinese cities, which are now highly mobile and rapidly transforming, exhibit commuting patterns that are highly complex (Shen et al., 2013; Zhou and Long, 2015). In this sense, the extent of wasteful commuting and the factors that influence this excess are important issues for urban planners and transportation engineers. This paper has examined route choice efficiency in suburban Beijing using a GPS-facilitated activity-travel survey. Actual routes for morning and evening commuting were compared with their shortest paths based on network distance by travel mode. Multilevel mixed effects generalized linear models were used to study the determinants of commuting efficiency. Several factors -commuting peaks, travel mode, number of non-work stops, work location, and built environment characteristics near the workplace - were found to influence route choice efficiency.

There are significant variations in commuting distance, number of stops and commuting efficiency between the morning and evening peaks. Residents have shorter commuting distances, fewer non-work stops and higher route choice efficiency during morning commuting than evening commuting. Residents face different levels of space-time constraints during different time periods. As most existing commuting studies focus exclusively on home-to-work trips in the morning ( $\mathrm{Li}$ et al., 2005; Sang et al., 2011) or average one-way commuting, the findings in this paper suggest that it is essential to distinguish morning commuting from evening commuting because residents have different choices in their routes and trip chains during different commuting peaks. As residents have fewer space-time constraints in the evening (Shen et al., 2015), they are more likely to take suboptimal routes and to engage in more discretionary activities (Bhat, 1997; Justen et al., 2013; Lockwood and Demetsky, 1993). However, the factors influencing these differences are far from understood. Further work is required to determine how commuting during morning and evening peaks is influenced by space-time constraints and other factors.

Regarding commuting efficiency, the findings in this paper complement other studies by 
indicating that traditional research has underestimated the level of commuting efficiency in cities. Consistent with Papinski and Scott (2013), this paper indicates that the actual routes of many residents do not follow the shortest paths. Further, commuters may detour to avoid congestion (unnecessary detours) or participate in non-work activities (necessary detours). In particular, making stops during morning commutes leads to more necessary detours and longer travel requirements. Rational residents may prefer to make more necessary detours, such as stopping at day-care centres, during the morning rather than making unnecessary detours. The difference in commuting efficiency according to the number of stops shows the optimal spatial location for individuals who have to complete more activities over a limited time. However, unnecessary detours, which are also common for these suburban residents, reflect terrible transportation conditions and/or incomplete transport information. Thus, the traditional approach of using Euclidean distance or the shortest network distance from home to work - without considering possible intended stops - may underestimate actual commuting distances.

Furthermore, while previous studies are focused on car travel (Papinski and Scott, 2013), this study provides an opportunity to compare differences in the levels of route choice efficiency among different travel modes. The findings suggest that non-motor travel leads to higher route choice efficiency than motor travel, and that automobile commuting tends to be the most inefficient travel mode. Adding to the discussion by Zhou and Long (2015) on the monocentric form in Beijing, the low efficiency of car users is connected to the fact that car ownership is generally intended to serve the entire household, which means that commuting by car fulfils family obligations such as driving children, conducting discretionary activities, etc. If commuting trips with several stops along the way, their routes are likely suboptimal (Zhao et al., 2015). Nevertheless, commuting by car does not lead to substantial major efficiencies in Chinese cities; instead, non-motor travel, including bicycling and walking, should be encouraged for short-distance commuters because of its high efficiency and low pollution.

From a planning and policy perspective, the study of route choice efficiency in the suburban areas of megacities and the relationship between the built environment and commuting characteristics 
may be used to help to develop new urban strategies and new transportation policies. Currently, there are hot debates in Western countries over whether spatial policies supporting new-urbanism-style neighbourhoods and job-housing proximity at the local level might reduce commuting distances and motorized travel (Cervero and Duncan, 2006; Pinjari et al., 2007). This paper's findings on job-housing relationships show that commuters to city centres exhibit higher efficiency than their counterparts in other suburban areas and that commuters who work in locations with better accessibility and lower density exhibit higher efficiency. Transport solutions should consider both commuting efficiency and the choice of non-motorized travel modes to better meet different transportation needs. The strategy of multi-centre development seems difficult to apply at this point. In the past decade, a series of policies encouraged job centres to be built in the suburbs. Our results show that a considerable percentage of commuters in Beijing work in distant areas, which causes serious mismatching between home and work (Fig. 2). Another serious problem is that infrastructures have not kept pace with population shifts, and thus the lack of metro lines (or stations) and low facility densities result in low route efficiency and wasteful commuting. Thus, we suggest that industrial development, housing construction, and public services should be considered together as an entire package in urban planning. It is essential to support life cycle planning (a structural estimation of infrastructure demand and supply, see Chai, 2013), and to practice personal travel planning (voluntary travel change, see Chatterjee, 2009). A change in behavioural patterns that is coordinated with the built environment based on societal needs is the key to successful future development.

This paper reveals some opportunities for future studies related to route choice efficiency. First, route choice efficiency can be measured by distance, time or speed. Due to the limitations of our database, this paper focuses solely on route distance. Commuting time and speed depends largely on network conditions, while traffic information and personal experience may also have different effects (Li et al., 2005; Thomas and Tutert, 2015), which is an interesting topic for future research. Second, trip-chaining is simplified as the dummy variable whether or not the commute contains stops. Although we distinguished between two types of detours based on the absence of non-work stops, we did not classify different types of non-work activities. Everyday activities such as 
visiting day-care centres may have a different impact on commuting efficiency than discretionary travel (such as for leisure). Furthermore, the discussion of whether non-work travel is excessive, and understandings of how best to measure its efficiency, may be different from the study of commuting. Effective trip-chaining for multiple purposes requires varied types of urban facilities and opportunities, such as the intersection of shopping trips with commercial density in specific locations. Future research should investigate these topics.

\section{References}

Beijing Statistic Bureau, 2013. 2012 Beijing Statistics Yearbook. Beijing: Beijing Statistic Bureau.

Beijing Transportation Research Centre, 2013. 2013 Annual Report. Beijing: Beijing Transportation Research Centre.

Bhat, C. R., 1996. A generalized multiple durations proportional hazard model with an application to activity behavior during the evening work-to-home commute. Transp. Res. B Methodol. 30(6), 465-480.

Bhat, C. R., 1997. Work travel mode choice and number of non-work commute stops. Transp. Res. B Methodol. 31(1), 41-54.

Bhat, C., 2001. Modeling the commute activity-travel pattern of workers: formulation and empirical analysis. Transp. Sci. 35(1), 61-79.

Cervero, R., Duncan, M., 2006. Which reduces vehicle travel more: jobs-housing balance or retail-housing mixing? J. Am. Plan. Assoc. 72(4), 475-490.

Chai, Y., 2013. Space-time behavior research in China: recent development and future prospect. Ann. Assoc. Am. Geographers 103(5), 1093-1099.

Chai, Y., Chen, Z., Liu, Y., Tana, Ma, X., 2014. Space-time behavior survey for smart travel planning in Beijing, China. In: Rasouli, S., Timmermans, H. (Eds), Mobile Technologies for Activity-Travel Data Collection and Analysis. Hershey, PA: IGI Global, pp. 79-90.

Chai, Y., Ta, N., Ma, J., 2016. The socio-spatial dimension of behavior analysis: Frontiers and 
progress in Chinese behavioral geography. J. Geogr. Sci. 26(8): 1243-1260.

Chatterjee, K., 2009. A comparative evaluation of large-scale personal travel planning projects in England. Transp. Policy 16(6), 293-305.

Chowdhury, T. A., Scott, D. M., Kanaroglou, P. S., 2013. Urban form and commuting efficiency: a comparative analysis across time and space.Urban Stud. 50(1), 191-207.

Ciscal-Terry, W., Dell'Amico, M., Hadjidimitriou, N. S., Iori, M., 2016. An analysis of drivers route choice behaviour using GPS data and optimal alternatives. J. Transp. Geogr. 51, $119-129$

De Palma, A., Lindsey, R., 2002. Comparison of morning and evening commutes in the Vickrey bottleneck model. Transp. Res. Rec. 1807, 26-33.

Ewing, R., Cervero, R., 2010. Travel and the built environment: a meta-analysis. J. Am. Plan. Assoc. 76(3), 265-294.

Feng, J., Dijst, M., Wissink, B., Prillwitz, J., 2013. The impacts of household structure on the travel behaviour of seniors and young parents in China. J. Transp. Geogr. 30, 117-126.

Feng, J., Zhou, Y., Wu, F., 2008. New trends of suburbanization in Beijing since 1990: from government-led to market-oriented. Reg. Stud. 42(1), 83-99.

Frank, L. D., Pivo, G., 1994. Impacts of mixed use and density on utilization of three modes of travel: single-occupant vehicle, transit, and walking. Transp. Res. Rec. 1466, 44-44.

Frost, M., Linneker, B., Spence, N., 1998. Excess or wasteful commuting in a selection of British cities. Transp. Res. A Policy Practice 32(7), 529-538.

Giuliano, G., Small, K., 1993. Is the journey to work explained by urban structure? Urban Stud. 30(9), 1485-1500.

Goldstein, H., 1986. Multilevel mixed linear model analysis using iterative generalized least squares. Biometrika 73(1), 43-56.

Hamilton, B. W., Röell, A., 1982. Wasteful commuting. J. Polit. Econ. 90(5), 1035-1053.

Horner, M. W., 2002. Extensions to the concept of excess commuting. Environ Plann. A 34(3), $543-566$.

Horner, M. W., 2004. Spatial dimensions of Urban commuting: a review of Major issues and their implications for future geographic Research. Prof. Geogr. 56(2), 160-173. 
Horner, M., Murray, A., 2002. Excess commuting and the modifiable areal unit problem. Urban Stud. 39(1), 131-139.

Horner, M. W., Wood, B. S., 2014. Capturing individuals' food environments using flexible space-time accessibility measures. Appl. Geogr. 51, 99-107.

Hu, Y., Wang, F., 2015. Decomposing excess commuting: a Monte Carlo simulation approach. $J$. Transp. Geogr. 44, 43-52.

Johnston-Anumonwo, I., 1997. Race, gender, and constrained work trips in Buffalo, NY, 1990. Prof. Geogr. 49(3), 306-317.

Justen, A., Martínez, F. J., Cortés, C. E., 2013. The use of space-time constraints for the selection of discretionary activity locations. J. Transp. Geogr. 33, 146-152.

Kanaroglou, P. S., Higgins, C. D., Chowdhury, T. A., 2015. Excess commuting: a critical review and comparative analysis of concepts, indices, and policy implications. J. Transp. Geogr. 44, 13-23.

Kim, S., 1995. Excess commuting for two-worker households in the Los Angeles metropolitan area. J. Urban Econ. 38(2), 166-182.

Klöckner, C. A., Matthies, E., 2004. How habits interfere with norm-directed behaviour: a normative decision-making model for travel mode choice. J. Environ. Psychol. 24(3), 319-327.

Krizek, K. J., 2003. Neighborhood services, trip purpose, and tour-based travel. Transportation 30(4), 387-410.

Kwan, M., 2000. Gender differences in space-time constraints. Area 32(2), 145-156.

Kwan, M., Chai, Y., Tana, 2014. Reflections on the similarities and differences between Chinese and US cities. Asian Geographer 31(2), 167-174.

Kwan, M., Kotsev, A., 2015. Gender differences in commute time and accessibility in Sofia, Bulgaria: a study using 3D geovisualisation. Geogr. J. 181(1), 83-96.

Li, H., Guensler, R., Ogle, J., 2005. Analysis of morning commute route choice patterns using global positioning system-based vehicle activity data. Transp. Res. Rec. 1926, 162-170.

Liu, W., Yan, X., Fang, Y., Cao, X., 2008. Related characteristics and mechanisms for excess commuting in Guangzhou (in Chinese). Acta Geogr. Sin. 63(10), 1085-1096. 
Lockwood, P. B., Demetsky, M. J., 1993. Nonwork travel - a study of changing behaviour. MSCE thesis, University of Virginia.

Loo, B. P. Y., Chow, A. S. Y., 2011. Jobs-housing balance in an era of population decentralization: an analytical framework and a case study. J. Transp. Geogr. 19(4), 552-562.Maat, K., Timmermans, H. J. P., 2009. Influence of the residential and work environment on car use in dual-earner households. Transp. Res. A Policy Pract. 43(7), 654-664.

McGuckin, N., Zmud, J., Nakamoto, Y., 2005. Trip-chaining trends in the United States: understanding travel behavior for policy making. Transp. Res. Rec. (1917), 199-204.

Murphy, E., 2009. Excess commuting and modal choice. Transp. Res. A Policy Pract. 43(8), $735-743$

Niedzielski, M. A., 2006. A spatially disaggregated approach to commuting efficiency. Urban Stud. 43(13), 2485-2502.

Niedzielski, M. A., Horner, M. W., Xiao, N., 2013. Analyzing scale independence in jobs-housing and commute efficiency metrics. Transp. Res. A Policy Pract. 58, 129-143.

Noland, R. B., Thomas, J. V., 2007. Multivariate analysis of trip-chaining behavior. Environ. Plann. B: Plann. Des. 34(6), 953-970.

O'Kelly, M. E., Lee, W., 2005. Disaggregate journey-to-work data: implications for excess commuting and jobs-housing balance. Environ. Plann. A 37(12), 2233-2252.

O’Kelly, M. E., Niedzielski, M. A., Gleeson, J., 2012. Spatial interaction models from Irish commuting data: variations in trip length by occupation and gender. J. Geogr. Syst. 14(4), $357-387$.

Papinski, D., Scott, D. M., 2013. Route choice efficiency: an investigation of home-to-work trips using GPS data. Environ. Plann. A 45(2), 263-275.

Pinjari, A. R., Pendyala, R. M., Bhat, C. R., Waddell, P. A., 2007. Modeling residential sorting effects to understand the impact of the built environment on commute mode choice. Transportation 34(5), 557-573.

Putnam, R., 2000. Bowling Alone. New York: Simon and Schuster.

Sang, S., O’Kelly, M., Kwan, M. P., 2011. Examining commuting patterns: results from a journey-to-work model disaggregated by gender and occupation. Urban Stud. 48, 
891-909.

Scheiner, J., Holz-Rau, C., 2012. Gendered travel mode choice: a focus on car deficient households. J. Transp. Geogr. 24, 250-261.

Schwanen, T., Dijst, M., 2003. Time windows in workers' activity patterns: empirical evidence from the Netherlands. Transportation 30(3), 261-283.

Shen, Y., Chai, Y., Kwan, M., 2015. Space-time fixity and flexibility of daily activities and the built environment: a case study of different types of communities in Beijing suburbs. $J$. Transp. Geogr. 47, 90-99.

Shen, Y., Kwan, M., Chai, Y., 2013. Investigating commuting flexibility with GPS data and 3D geovisualization: a case study of Beijing, China. J. Transp. Geogr. 32, 1-11.

Shiftan, Y., Barlach, Y., 2002. Effect of employment site characteristics on commute mode choice. Transp. Res. Rec. 1781, 19-25.

Small, K. A., Song, S., 1992. "Wasteful" commuting: a resolution. J. Polit. Econ. 100(4), 888-898.

Snijders, T., Bosker, R., 1999. Multilevel Analysis: An Introduction to Basic and Applied Multilevel Analysis. London: Sage Publishing House.

Ta, N., Kwan, M. P., Chai, Y., Liu, Z., 2015. Gendered space-time constraints, activity participation and household structure: a case study using a GPS-based activity survey in suburban Beijing, China. Tijdschrift voor economische en sociale geografie. doi:10.1111/tesg.12167.

Tana, Kwan, M. P., Chai, Y., 2016. Urban form, car ownership and activity space in inner suburbs: a comparison between Beijing (China) and Chicago (United States). Urban Stud. 53(9), 1784-1802.

Thomas, T., Tutert, B., 2015. Route choice behavior in a radial structured urban network: do people choose the orbital or the route through the city center? J. Transp. Geogr. 48, 85-95.

Urry, J., 2007. Mobilities. Cambridge, UK: Polity

Urry, J., 2012. Social networks, mobile lives and social inequalities. J. Transp. Geogr. 21, 24-30.

Wang, D., Chai, Y., 2009. The jobs-housing relationship and commuting in Beijing, China: the 
legacy of Danwei. J. Transp. Geogr. 17(1), 30-38.

Ye, X., Pendyala, R. M., Gottardi, G., 2007. An exploration of the relationship between mode choice and complexity of trip chaining patterns. Transp. Res. B Methodol. 41(1), 96-113.

Zhao, P., Lü, B., De Roo, G. d, 2011. Impact of the jobs-housing balance on urban commuting in Beijing in the transformation era. J. Transp. Geogr. 19(1), 59-69.

Zhao, Y., Chai, Y., 2013. Residents' activity-travel behavior variation by communities in Beijing, China. Chin. Geogr. Sci. 23(4), 492-505.

Zhao, Y., Dijst, M., Chai, Y., 2015. Between haven and heaven: a comparison between Beijing (China) and Utrecht (the Netherlands). Urban Stud. doi:10.1177/0042098015596106.

Zhou, J., Long, Y., 2015. Losers and Pareto optimality in optimizing commuting patterns. Urban Stud. doi:10.1177/0042098015594072.

Zhou, J., Murphy, E., Long, Y., 2014a. Commuting efficiency in the Beijing metropolitan area: an exploration combining smartcard and travel survey data. J. Transp. Geogr. 41, 175-183.

Zhou, J., Z., Zhang, C., Chen, X., Huang, W., Yu, P., 2014b. Has the legacy of Danwei persisted in transformations? The jobs-housing balance and commuting efficiency in Xi'an. $J$. Transp. Geogr. 40, 64-76. 
Table 1 Sample characteristics

\begin{tabular}{|c|c|c|c|}
\hline Variables & Classification & $\mathbf{N}$ & $\%$ \\
\hline \multirow{2}{*}{ Gender } & Male & 78 & 48.8 \\
\hline & Female & 82 & 51.3 \\
\hline \multirow{2}{*}{ Hukou } & Beijing hukou & 136 & 85.0 \\
\hline & Non-Beijing hukou & 24 & 15.0 \\
\hline \multirow{3}{*}{ Education } & Less than high school & 28 & 17.5 \\
\hline & College or university & 101 & 63.1 \\
\hline & Graduate & 31 & 19.4 \\
\hline \multirow{3}{*}{ Personal monthly income } & $2000 \mathrm{RMB}$ or lower & 15 & 9.4 \\
\hline & 2000-6000 RMB & 99 & 61.9 \\
\hline & More than $6000 \mathrm{RMB}$ & 46 & 28.8 \\
\hline \multirow{5}{*}{ Age } & $20-29$ & 27 & 16.9 \\
\hline & $30-39$ & 83 & 51.9 \\
\hline & $40-49$ & 33 & 20.6 \\
\hline & $50+$ & 17 & 10.6 \\
\hline & Single & 7 & 4.4 \\
\hline \multirow{4}{*}{ Household structure } & Married without child & 66 & 41.3 \\
\hline & Nuclear family with child & 55 & 34.4 \\
\hline & Extended family with child & 32 & 20.0 \\
\hline & Local area & 46 & 28.8 \\
\hline \multirow[t]{2}{*}{ Work location } & City centre & 58 & 36.3 \\
\hline & Other area & 56 & 35 \\
\hline \multicolumn{2}{|c|}{ Total } & \multicolumn{2}{|c|}{160} \\
\hline
\end{tabular}


Table 2 Mean commuting characteristics and Paired-Sample t-test Results for Morning and Evening commuting

\begin{tabular}{ccccc}
\hline Total sample & $\mathbf{N}$ & Actual commuting distance (km) & RDI (\%) & Stops \\
\hline Morning commuting & 329 & 15.81 & 55 & .09 \\
Evening commuting & 329 & 16.09 & 61 & .18 \\
Total & 658 & 15.95 & 58 & .13 \\
Paired sample t-test & 329 & .004 & .026 & .003 \\
\hline Sample with no stops & $\mathbf{N}$ & Actual commuting distance (km) & RDI (\%) & \\
\hline Morning commuting & 303 & 15.71 & 47 & \\
Evening commuting & 278 & 16.66 & 59 & \\
Total & 581 & 16.16 & 53 & \\
Paired sample $\boldsymbol{t}$-test & 258 & .011 & .028 & \\
\hline
\end{tabular}


Table 3 Average commuting distance and RDI values for independent variables

\begin{tabular}{|c|c|c|c|c|c|c|c|c|c|c|c|}
\hline & & \multicolumn{2}{|c|}{$\begin{array}{l}\text { Morning } \\
\text { commuting } \\
\text { distance }(\mathbf{k m})\end{array}$} & \multicolumn{2}{|c|}{$\begin{array}{l}\text { Evening } \\
\text { commuting } \\
\text { distance }(\mathbf{k m})\end{array}$} & \multicolumn{2}{|c|}{$\begin{array}{l}\text { RDI for } \\
\text { Morning } \\
\text { commuting (\%) }\end{array}$} & \multicolumn{2}{|c|}{$\begin{array}{l}\text { RDI for Evening } \\
\text { commuting (\%) }\end{array}$} & \multicolumn{2}{|c|}{ Number of stops } \\
\hline & & Mean & ANOVA & Mean & ANOVA & Mean & ANOVA & Mean & ANOVA & Mean & ANOVA \\
\hline \multirow{3}{*}{ Stops } & 0 & 15.56 & .112 & 16.66 & .113 & 46 & .000 & 59 & .519 & & \\
\hline & 1 & 16.92 & & 13.58 & & 78 & & 75 & & & \\
\hline & $2+$ & 28.87 & & 9.46 & & 64 & & 54 & & & \\
\hline \multirow{5}{*}{$\begin{array}{l}\text { Travel } \\
\text { mode }\end{array}$} & Car & 16.55 & .000 & 17.34 & .000 & 69 & .143 & 76 & .120 & .17 & .097 \\
\hline & Walk & 1.74 & & 2.14 & & 35 & & 48 & & .04 & \\
\hline & Bicycle & 5.51 & & 6.27 & & 40 & & 66 & & .05 & \\
\hline & $\begin{array}{l}\text { Public } \\
\text { transit }\end{array}$ & 16.72 & & 17.21 & & 42 & & 38 & & .14 & \\
\hline & Other & 32.86 & & 32.08 & & 61 & & 59 & & .08 & \\
\hline
\end{tabular}


Table 4 Multilevel linear regression models for RDI values

\begin{tabular}{|c|c|c|c|c|c|c|c|c|}
\hline & \multicolumn{2}{|c|}{$\begin{array}{l}\text { Model 1: } \\
\text { Total } \\
\text { commuting }\end{array}$} & \multicolumn{2}{|c|}{$\begin{array}{c}\text { Model 2: } \\
\text { Commuting } \\
\text { with no stops }\end{array}$} & \multicolumn{2}{|c|}{$\begin{array}{l}\text { Model 3: } \\
\text { Morning } \\
\text { commuting }\end{array}$} & \multicolumn{2}{|c|}{$\begin{array}{l}\text { Model 4: } \\
\text { Evening } \\
\text { commuting }\end{array}$} \\
\hline & Coef. & $\mathrm{P}$ & Coef. & $\mathrm{P}$ & Coef. & $\mathrm{P}$ & Coef. & $\mathrm{P}$ \\
\hline \multicolumn{9}{|l|}{ Commuting time (Morning=ref. ) } \\
\hline Evening & 0.14 & 0.046 & 0.16 & 0.036 & - & - & - & - \\
\hline Female $($ Male $=$ ref. $)$ & -2.64 & 0.015 & -2.49 & 0.017 & -2.65 & 0.013 & -2.55 & 0.021 \\
\hline \multicolumn{9}{|l|}{ Household structure $($ Single $=$ ref. $)$} \\
\hline Married without child & -1.44 & 0.124 & -1.32 & 0.141 & -1.22 & 0.177 & -1.35 & 0.155 \\
\hline Nuclear family with child & -1.65 & 0.079 & -1.56 & 0.084 & -1.55 & 0.087 & -1.38 & 0.143 \\
\hline Extended family with child & -1.17 & 0.22 & -1.07 & 0.239 & -1 & 0.273 & -1.17 & 0.222 \\
\hline Married without child $*$ female & 2.51 & 0.024 & 2.47 & 0.022 & 2.18 & 0.047 & 2.74 & 0.016 \\
\hline Nuclear family with child*female & 2.6 & 0.021 & 2.4 & 0.027 & 2.7 & 0.015 & 2.28 & 0.048 \\
\hline Extended family with child $*$ female & 1.64 & 0.164 & 1.55 & 0.173 & 1.6 & 0.171 & 1.53 & 0.205 \\
\hline \multicolumn{9}{|l|}{ Number of stops (None=ref. ) } \\
\hline 1 & 0.1 & 0.469 & - & - & 0.82 & 0.013 & -0.07 & 0.704 \\
\hline $2+$ & -0.54 & 0.099 & - & - & -0.32 & 0.655 & -0.39 & 0.391 \\
\hline \multicolumn{9}{|l|}{ Age $(50+=$ ref. $)$} \\
\hline $20-29$ & -0.39 & 0.432 & -0.48 & 0.329 & -0.26 & 0.607 & -0.36 & 0.489 \\
\hline $30-39$ & -0.62 & 0.196 & -0.54 & 0.249 & -0.48 & 0.324 & -0.51 & 0.307 \\
\hline $40-49$ & -0.32 & 0.44 & -0.37 & 0.38 & -0.23 & 0.6 & -0.27 & 0.538 \\
\hline \multicolumn{9}{|l|}{ Hukou (Non-Beijing hukou=ref. ) } \\
\hline Beijing hukou & -0.16 & 0.603 & -0.13 & 0.662 & -0.16 & 0.606 & -0.21 & 0.5 \\
\hline \multicolumn{9}{|l|}{ Personal income (More than 6000} \\
\hline \multicolumn{9}{|l|}{ RMB=ref. ) } \\
\hline $2000 \mathrm{RMB}$ or less & 0.61 & 0.169 & 0.82 & 0.058 & 0.33 & 0.474 & 0.82 & 0.076 \\
\hline 2000-6000 RMB & 0.81 & 0.001 & 0.79 & 0.001 & 0.76 & 0.003 & 0.72 & 0.005 \\
\hline \multicolumn{9}{|l|}{ Education (High school or } \\
\hline \multicolumn{9}{|l|}{ lower=ref. ) } \\
\hline College/University & 0.44 & 0.223 & 0.41 & 0.244 & 0.39 & 0.297 & 0.41 & 0.277 \\
\hline Graduate school & 0.51 & 0.268 & 0.55 & 0.225 & 0.39 & 0.408 & 0.46 & 0.333 \\
\hline \multicolumn{9}{|l|}{ Travel mode (Bicycle $=$ ref. $)$} \\
\hline Car & 1.14 & 0 & 1.1 & 0 & 0.92 & 0.002 & 1.09 & 0.001 \\
\hline Walking & -0.01 & 0.978 & 0.03 & 0.943 & -0.37 & 0.526 & -0.49 & 0.333 \\
\hline Public transit & 0.57 & 0.033 & 0.55 & 0.04 & 0.48 & 0.154 & 0.55 & 0.112 \\
\hline Other & 1.15 & 0.001 & 1.2 & 0.002 & 1.29 & 0.007 & 0.82 & 0.084 \\
\hline \multicolumn{9}{|l|}{ Work location $($ Other place $=$ ref. $)$} \\
\hline Local area & 0.93 & 0.001 & 0.75 & 0.007 & 0.95 & 0.001 & 0.92 & 0.002 \\
\hline City centre & -0.5 & 0.085 & -0.57 & 0.044 & -0.42 & 0.15 & -0.51 & 0.09 \\
\hline Built environment in residential area & & & & & & & & \\
\hline
\end{tabular}




\begin{tabular}{lcccccccc}
\hline Distance to the nearest railway station & -0.03 & 0.829 & -0.02 & 0.902 & -0.07 & 0.612 & 0 & 0.982 \\
Road network density & 0.02 & 0.444 & 0.02 & 0.324 & 0.03 & 0.281 & 0.01 & 0.578 \\
Facility density & -0.01 & 0.333 & -0.01 & 0.266 & -0.01 & 0.366 & -0.01 & 0.295 \\
Built environment in working area & & & & & & & & \\
Distance to the nearest railway station & 0.15 & 0.066 & 0.14 & 0.067 & 0.16 & 0.045 & 0.13 & 0.112 \\
Road network density & -0.03 & 0.079 & -0.03 & 0.051 & -0.02 & 0.11 & -0.03 & 0.081 \\
Facility density & 0.01 & 0.013 & 0.02 & 0.005 & 0.01 & 0.028 & 0.01 & 0.014 \\
cons & 2.89 & 0.059 & 2.62 & 0.077 & 2.74 & 0.073 & 3.37 & 0.031 \\
var(cons) & 1.12 & & 0.10 & & 0.74 & & 0.96 & \\
var(e.Inrdi)| & 0.84 & & 0.82 & & 1.13 & & 0.83 & \\
N & 658 & & 581 & & 329 & & 329 & \\
Wald Chi ${ }^{2}$ & 93.93 & & 83.52 & & 75.2 & & 66.01 & \\
Log likelihood & -1015. & -891.8 & & -551.6 & & -527.8 & \\
\hline
\end{tabular}




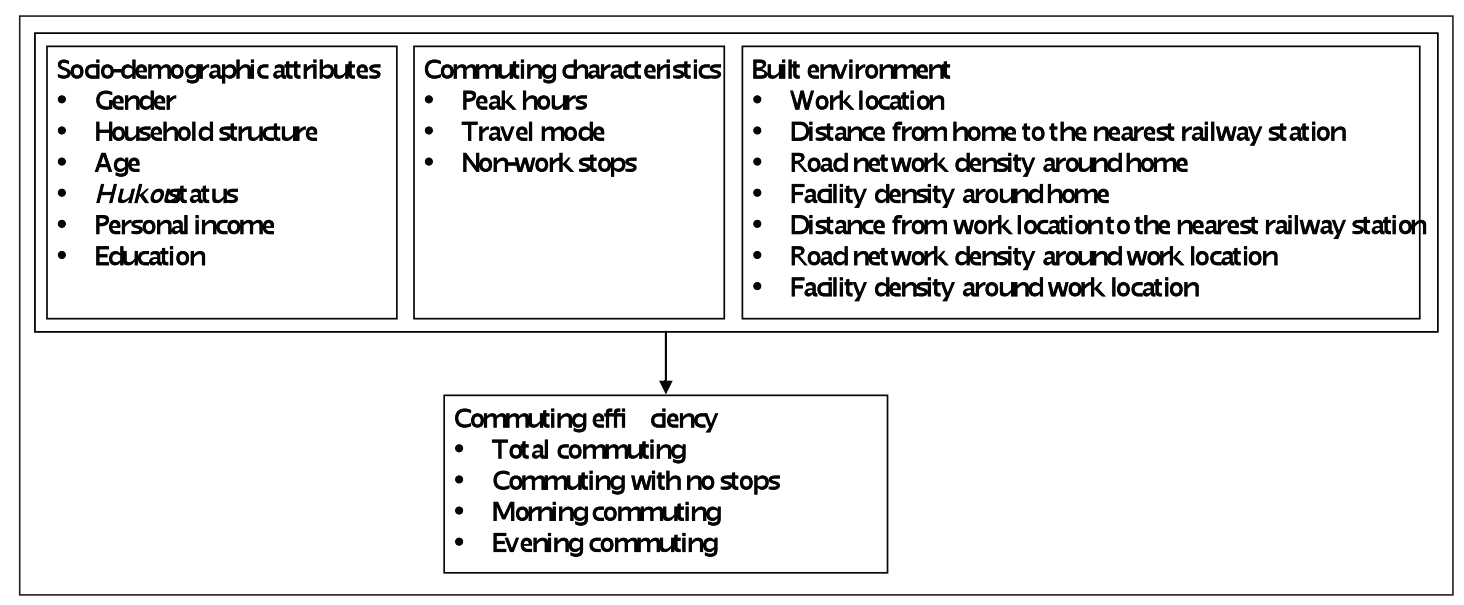

Figure 1 Conceptual model 


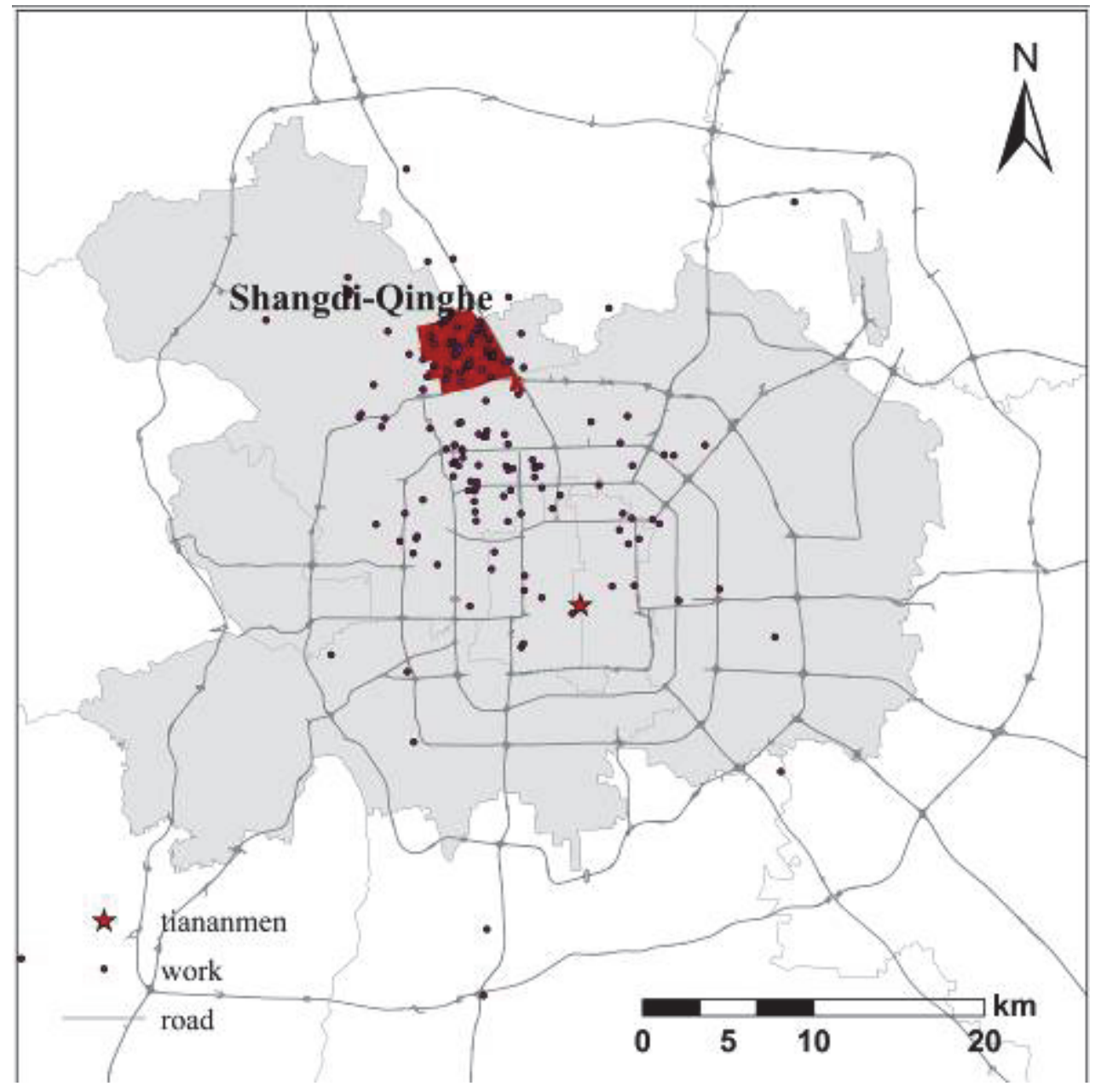

Figure 2 Study area and working locations of respondents 